\title{
Escola, currículo e identidades juvenis: efeitos de sentido no discurso de professores ${ }^{1}$
}

\author{
School, curriculum and youth identities: meaning effects from the teachers' discourse
Escuela, currículo e identidades juveniles: efectos de sentido en el discurso de profesores

\author{
DORIS MARIA LUZZARDI FISS* \\ RAFAEL D'ÁVILA BARROS**
}

\begin{abstract}
RESUMO - Este artigo ${ }^{2}$ tematiza a escola no que se refere às suas funções e às identidades juvenis a partir do estabelecimento de interlocução com 23 professores da Educação Básica. Trata-se de pesquisa realizada em 2012 que possibilita trazer reflexões sobre os níveis de objetivação do currículo, a construção do planejamento didáticopedagógico e a compreensão dos alunos como sujeitos socioculturais. Tais elementos são considerados a partir da análise discursiva de formulações produzidas pelos professores em entrevista. Considerando 46 depoimentos, concluise, a partir da análise, que, para os professores, permanece sendo um desafio enxergar seus alunos como sujeitos com uma trajetória de vida específica que habitam a escola das mais diversas formas. Produzir um planejamento que tenha intencionalidade e, ao mesmo tempo, seja flexível se mostra como um segundo desafio ao trabalho docente. Nesse sentido, motivar um exercício de alteridade, onde os professores se coloquem no lugar de alguém que descobre o mundo a partir da investigação curiosa, com auxílio de outros sujeitos, pode ser um caminho fértil para mudanças pessoais e coletivas de que resultem a invenção de outras propostas possíveis de metodologias, planos de ensino e práticas docentes.
\end{abstract}

Palavras-chave - Identidades discentes. Currículo. Docência. Discurso pedagógico. Análise de discurso.

\begin{abstract}
This article thematizes the school due to its functions and juvenile identities since the establishment of interlocution with 23 teachers from Basic Education. This is from the research, done in 2012, which enables to bring reflections on the levels of objectification of the curriculum, the construction of the didactic-pedagogic planning and the students' comprehension as sociocultural subjects. Those aspects are considered based on discursive analysis of formulations produced by the teachers. Considering 46 testimonials, is is concluded from the analysis that, to the teachers, it remains being a challenge to see their students as subjects with a specific life trajectory that inhabit the school in many different ways. To produce a planning that has intentionality, and at the same time, is flexible seems to be a second challenge to the faculty work. In that sense, motivate an exercise in alterity, where the teachers put themselves in the place of the one who discovers the world from the curious investigation with the help of other subjects can be fertile path to personal and collective changes resulting from the invention of other proposals of possible methodologies, lesson plans and teaching practices.
\end{abstract}

Keywords - Students identities. Curriculum. Faculty. Pedagogical discourse. Discourse analysis.

RESUMEN - Este artículo tematiza la escuela en relación a sus funciones y las identidades juveniles a partir de la apertura de interlocución con 23 maestros de educación básica. Se trata de una investigación realizada en el año 2012 que permite realizar reflexiones sobre los niveles de objetivación del currículo, la construcción de la planificación didáctico-pedagógica y la comprensión de los alumnos como sujetos socio-culturales. Tales elementos se consideran a partir del análisis discursivo de formulaciones producidas por los profesores en la entrevista. Considerando 46 testimonios, se concluye, a partir del análisis que, para los profesores, sigue siendo un desafío ver a sus alumnos como sujetos con una trayectoria de vida específica que habitan la escuela de las más diversas maneras. Producir una planificación que tenga intencionalidad y, al mismo tiempo, sea flexible se muestra como un segundo desafío para el trabajo docente. En este sentido, motivar un ejercicio de alteridad, donde los profesores se pongan en el lugar de alguien que descubre el mundo a partir de la investigación curiosa, con la ayuda de otros sujetos, puede ser un camino fértil para los cambios personales y colectivos que dan lugar a la invención de otras propuestas posibles de metodologías, planes de enseñanza y prácticas docentes.

Palabras clave - Identidades discentes. Currículo. Docencia. Discurso pedagógico. Análisis del discurso.

\footnotetext{
*Doutora em Educação pela Universidade Federal do Rio Grande do Sul (Porto Alegre, RS, Brasil) e professora na Universidade Federal do Rio Grande do Sul (Porto Alegre, RS, Brasil).E-mail:<fiss.doris@gmail.com>.

**Graduando em Ciências Sociais pela Universidade Federal do Rio Grande do Sul (Porto Alegre, RS, Brasil). E-mail: <orafaelbarros@gmail.com>.
} 


\section{INTRODUÇÃO}

Este artigo tematiza a escola no que se refere às suas funções e às identidades juvenis a partir do estabelecimento de interlocução com 23 professores da Educação Básica que atuam na rede pública (estadual e municipal) e na rede privada de Porto Alegre e Região Metropolitana. Trata-se de uma pesquisa realizada em 2012 que, como propõe Minayo (2007), "trabalha com o universo dos significados, dos motivos, das aspirações, das crenças, dos valores e das atitudes" (p. 21) dos sujeitos, possibilitando, a partir da análise discursiva de seus enunciados, trazer reflexões sobre os níveis de objetivação do currículo, a construção do planejamento didático-pedagógico e a compreensão dos alunos como sujeitos socioculturais.

Foram feitas quatro perguntas aos professores - Quem são os seus alunos? Por que os seus alunos vão para a escola? Como você constrói o seu planejamento? Você o modifica ao longo do ano? -, sendo elas próprias as questões de pesquisa. $\mathrm{O}$ campo discursivo de referência compreende o discurso pedagógico, na perspectiva dos professores, os quais se reportam às práticas de ensino na escola. Os recortes sobre os quais se centra a análise, apresentados neste artigo, consistem nas respostas produzidas a partir das questões feitas. No que se refere especificamente à perspectiva interpretativa adotada, a da Análise de Discurso, salientamos que o uso da língua pelos sujeitos que enunciam manifesta os enunciados discursivos que assumem, apontando a posições no discurso pedagógico. Na interpretação dos enunciados dos professores, buscamos efeitos de sentido articulados às negociações que eles assumem com os alunos, com a escola e com os muitos fatores que interferem em sua prática.

\section{DiÁlOgOS ANTERIORES}

As perguntas feitas aos professores, e também as suas respostas, estão carregadas de referências a currículo e planejamento. Em função disso, procuramos entender currículo a partir dos significados que a ele são conferidos e de suas dinâmicas de produção na escola. Sacristán (2000), a este respeito, destaca que

o currículo é um objeto que se constrói no processo de configuração, implantação, concretização e expressão de determinadas práticas pedagógicas e em sua própria avaliação, como resultado das diversas intervenções que nele se operam. Seu valor real para os alunos, que aprendem seus conteúdos, depende desses processos de transformação aos quais se vê submetido. [...] Tratase, pois, de um campo de atividade para múltiplos agentes, com competências divididas em proporção diversa, que agem através de mecanismos peculiares em cada caso (p. 102).
Apropriamo-nos dos níveis de currículo a partir do que falam sobre este assunto dois autores em específico: J. Gimeno Sacristán (2000; 2007a; 2007b; 2007c) e Angel I. Pérez Gómez (2007). Sacristán (2000) representa os níveis de objetivação do significado do currículo por meio de um esquema:

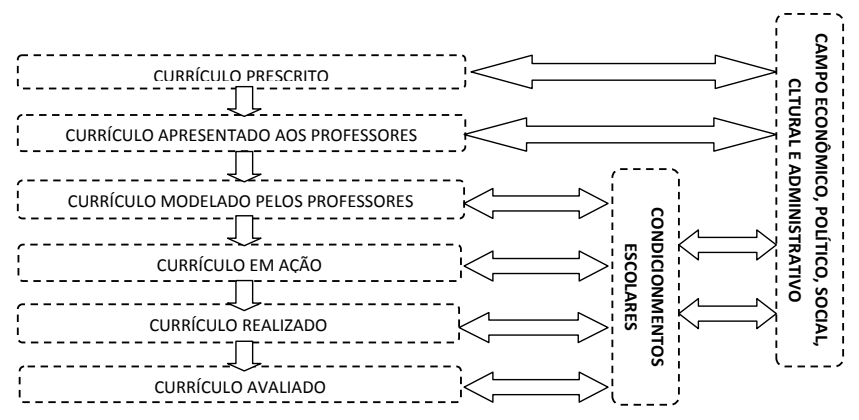

Figura 1 - A objetivação do currículo no processo de seu desenvolvimento. Fonte: SACRISTAN, 2000, p. 105.

Segundo Sacristán $(2000 ; 2007 a)$, o currículo prescrito corresponde às prescrições administrativas ou políticas que orientam as práticas curriculares, constituindo-se em um tipo de "orientação do que deve ser seu conteúdo, principalmente em relação à escolaridade obrigatória" (2000, p. 104). A política curricular governa as decisões gerais e se manifesta numa certa ordenação jurídico-administrativa. Como ressalta Sacristán (2000),

A política curricular pode ser sistematizada em torno de uma série de aspectos ou itens que contribuem para lhe dar forma e para que logre, sejam quais forem os caminhos, sua função reguladora. Analisando esses caminhos de intervenção compreenderemos o sentido do currículo como campo no qual se expressa uma ação que, não sendo de tipo pedagógico, tem amplo poder de enquadrar o que é a prática no ensino (p. 110).

O currículo apresentado aos professores tem como instrumento os livros didáticos a partir dos quais são transmitidos o significado e os conteúdos do currículo prescrito que, embora impacte de modo importante sobre o estabelecimento e definição das opções pedagógicas em linhas mais gerais, não incide da mesma forma sobre o trabalho cotidiano dos docentes. Alguns elementos ajudam a compreender este "limite" das influências exercidas pelo currículo prescrito: a complexidade da prática pedagógica associada a várias necessidades de ordem social e cultural; a necessidade de conexão de conhecimentos de tipo muito diverso em função das peculiaridades dos alunos com que o docente trabalha, suas culturas e as características do ambiente educativo; a formação docente ainda problemática ou, pelo menos, não 
continuada e sistemática; as condições de produção da docência (o número de alunos a ser atendido e as diferentes funções que o professor é instado a desempenhar - atenção aos alunos, correção dos trabalhos, burocracia própria de algumas atividades - a que se agregam as de planejar o ensino e ensinar).

Desse conjunto de fatores resultam, pelo menos, duas consequências: a impossibilidade de o currículo prescrito exercer controle eficaz sobre a ação docente e a busca de apoios didáticos, ou "pré-elaborações do currículo para seu ensino" (SACRISTÁN, 2000, p. 149), pelo professor - os livros didáticos e outros materiais que funcionam como "guias" da prática pedagógica. A dependência estabelecida pelo professor em relação a algum tipo de suporte que estruture o currículo, organize seus conteúdos e proponha sugestões de trabalho é bastante conhecida, existindo pesquisas relevantes sobre esta realidade (FREITAG; MOTTA; COSTA, 1987; MEGID NETO; FRACALANZA, 2006; EMMEL; ARAÚJO, 2012; CHOPPIN, 2004). No entanto, o problema nevrálgico é que, consoante adverte Sacristán (2000), ao docente são atribuídas

complexas missões [...] com grupos numerosos de alunos e em condições nem sempre favoráveis. Para o professor não é fácil passar de princípios ideais para a prática coerente com os mesmos, a não ser à medida que possa planejar uma estrutura de tarefas adequadas na qual se conjuguem conteúdos curriculares e princípios pedagógicos (p. 149).

Se o currículo molda os professores, é também moldado por eles. No nível do currículo modelado, os docentes correspondem a "tradutores" que intervêm na configuração dos significados das propostas curriculares. O plano de ensino se constitui num momento importante nessa "tradução": os professores modelam, criticam e até refazem planejamentos, tomando seu registro como ponto de partida. Todavia, mesmo que pressupondo a participação do docente, esta fase de objetivação do currículo não outorga autonomia tão ampla a ele: movimentando-se por entre a posição de planejador e a de gestor da prática, o "professor não seleciona as condições nas quais realiza seu trabalho e, nessa medida, tampouco pode escolher muitas vezes como desenvolvê-lo" (SACRISTÁN, 2000, p. 167). A profissão docente se constitui a partir de um componente pessoal e criativo, sujeito às possibilidades da formação e do desenvolvimento do pensamento profissional autônomo dos professores, mas se exerce num universo que predetermina uma parcela significativa dos significados e das finalidades do currículo. O professor é como um planejador intermediário entre diretrizes que lhe são apresentadas (e referem os níveis de currículo prescrito e apresentado respectivamente) e as condições concretas, e muito reais, de produção da prática.

Numa interpretação preliminar das respostas dos professores entrevistados, evidenciamos preocupação, por parte deles, em tornar evidentes as formas pelas quais planejam suas atividades em sala de aula e o que interfere nelas. O plano de ensino é tomado por eles como sinônimo de currículo e, neste contexto de análise, quer significar "confecção de um apontamento, rascunho, croqui, esboço ou esquema que representa uma ideia, um objeto, uma ação ou sucessão de ações, uma aspiração ou projeto que serve como guia para ordenar a atividade de produzi-lo efetivamente" (SACRISTÁN, 2007b, p. 197). Ele se tece num espaço de permanente tensão. Desde uma concepção globalizadora de currículo, o plano se configura como oportunidade de tratamento das informações para além das fronteiras de cada área de conhecimento - o que implica assumir compromisso com a articulação entre ensino e criação de experiências de aprendizagem para os alunos. Se for considerado como parâmetro o paradigma dominante (SANTOS 1988; 2000; 2006; 2008), o plano resultará numa organização científica de procedimentos de instrução que tendem a desconsiderar a multidimensionalidade das situações de ensino, implicando a "execução de certas práticas ajustadas a normas técnicas” (SACRISTÁN, 2007b, p. 205).

Tendo como referência o texto "Elaboração de um projeto de ensino" (CALDEIRA, 2002), que estabelece relação com compreensões desenhadas por Sacristán (2000; 2007c), entendemos que, para construir um plano de ensino, é preciso trabalhar com a escola que temos, com a escola que nos é apresentada, com os alunos que ali existem e que ali estão. O plano de ensino de cada disciplina precisa abarcar outras dimensões para além da lista de conteúdos, precisa conter a concepção pedagógica do professor, as percepções dele sobre a conjuntura social em que seus alunos estão envolvidos, bem como seu posicionamento diante de tudo isso. Há uma dimensão de intencionalidade por parte dos professores nesta concepção de ensino. Por isso, a existência de um planejamento se faz muito importante: a possibilidade de organizar ações e estratégias pedagógicas permite ao docente enxergar-se também como protagonista no processo de ensino e aprendizagem.

Ao afirmarmos que construir um plano de ensino é projetar ideias e ações, queremos também tornar evidente que é uma das possibilidades de ação política dos docentes. A ação com "intencionalidade significa ação política, comprometida com a construção de um determinado projeto de bem e de sociedade" (CALDEIRA, 2002, p. 12). Este comprometimento político não visa a um convencimento ideológico; muito ao contrário, ousa 
provocar os estudantes a pensarem sobre suas ações, consequências e possíveis alternativas de constituição de relações humanas mais fraternas e solidárias.

A realização dos planos de ensino demanda também flexibilidade, pois o docente precisa deixar-se ser afetado pelo cotidiano dos alunos. Geraldi (2010) defende que a aula é um local de acontecimentos, um local aonde o inusitado vem habitar naquilo que está organizado de modo a tencionar e desestabilizar a ordem preestabelecida. O planejamento que o docente constrói não pode se fechar àquilo que acontece na vida dos estudantes. Os conteúdos desconectados da vida cotidiana se tornam saberes deslocados, desenraizados e desorientados frente ao que os alunos estão vivendo.

O currículo em ação se relaciona ao modo pelo qual os professores descrevem como podem operacionalizar os conteúdos de modo a privilegiar suas opções metodológicas. Ele se relaciona à prática real guiada por esquemas teóricos e práticos do professor, que se concretiza nas tarefas acadêmicas a partir das quais se evidenciam os significados que os educadores conferem à prática pedagógica. O currículo realizado envolve a constatação de que as consequências do currículo influenciam nas aprendizagens dos alunos, nos modos de socialização das práticas operadas pelos professores e em níveis sociais e familiares outros. Por fim, o currículo avaliado se destaca pela contradição a partir da qual se constitui: ao mesmo tempo em que corresponde a um instrumento que permite a professores, alunos e comunidade escolar reconstruir continuamente os planos de trabalho, os critérios adotados para avaliação do currículo terminam por afetar as práticas, os professores e os alunos, definindo o que se espera deles e como eles devem se constituir.

Todos esses níveis se comunicam e atravessam o cotidiano dos sujeitos envolvidos e das instituições de ensino. Não é possível defender um nível de forma a excluir os demais; todos incidem sobre a construção do plano de ensino dos professores. Eles coexistem no mesmo tempo e espaço escolar, representando possibilidades e limitações.

\section{Algumas anÁlises}

Santos (1988) problematiza a ciência moderna e a emergência de uma ciência pós-moderna a partir do tensionamento entre os paradigmas dominante e emergente. Por um lado, o autor faz críticas à ciência moderna e a descreve considerando as seguintes características: problemática das leis universais; dimensão do controle e dominação da vida; regulação da natureza; arrogância do saber científico frente a outras formas de compreensão do mundo; conhecimento quantificado e fragmentado. Por outro lado, o paradigma emergente se compromete com um conhecimento prudente para uma vida decente, propondo: um conhecimento não dualista; galerias temáticas por onde os conhecimentos circulam; pluralidade metodológica; transgressão literária; autoconhecimento durante a construção do conhecimento; processo de tradução e modificação do senso comum. Se consideradas, como sugere Sacristán (2007b), as condições muito concretas de produção da docência que evidenciam a "prática de ensino [como] atividade que existe em certas condições, próprias do tipo de escolarização dominante" (p. 206), se evidencia, na prática pedagógica, uma tensão ainda bastante significativa entre as duas tradições descritas por Santos (1988).

Considerando nossos referenciais e a opção pela Análise de Discurso, buscamos identificar traços de cada um dos dois paradigmas explorados por Santos (1988), utilizando-os como ferramentas de pensamento que possibilitam melhor compreender os professores e suas escolhas. Para as perguntas - "Quem são os seus alunos? Por que os seus alunos vão para a escola?" e "Como você constrói seu planejamento? Você o modifica ao longo do ano?" - foram analisadas 46 respostas. Optamos por evidenciar os efeitos de sentido a partir das respostas e, assim, desenvolver considerações sobre eles conforme é proposto por Michel Pêcheux (1997) quando destaca a importância da passagem pela língua enquanto momento inerente ao processo analítico-discursivo. Ressaltamos que, a fim de organizar as análises, os efeitos de sentido surpreendidos foram explorados a partir dos subtítulos das perguntas.

\section{1 "Quem são os seus alunos? Por que os seus alunos vão para a escola?"}

$\mathrm{O}$ efeito de sentido homogeneização do sujeito foi evidenciado em 12 respostas ${ }^{3}$. Os professores reconhecem seus alunos através de alguns estereótipos acerca do pertencimento social e da faixa etária: são adolescentes, jovens ou adultos provenientes de classes sociais distintas, em alguns casos, economicamente empobrecidas "adolescentes [...] de classe popular da periferia" (EF); "filhos da classe A" (D); "representantes das periferias da cidade" (FJS); "da vila Cruzeiro" (ME); "adolescentes de classe média baixa" (EF); "de famílias que têm condições financeiras" (ASW); "de uma classe humilde" (P3); "adolescentes em sua maioria da classe média" (P2); "de classe média e baixa" (J e AC); "de classe média" (J5); "alunos da Modalidade Jovens e Adultos" (MM).

Considerar os alunos apenas em função das classes sociais ou de seu grupo etário homogeneíza os sujeitos na medida em que eles não são reconhecidos como sujeitos socioculturais, isto é, constitutivamente heterogêneos e 
afetados por relações de outras ordens também. A este respeito, convém lembrar Stuart Hall (2003) e suas considerações sobre o que está em jogo quando o foco são as identidades. $\mathrm{O}$ autor adverte que

O sujeito, previamente vivido como tendo uma identidade unificada e estável, está se tornando fragmentado; composto não de uma única, mas de várias identidades, algumas vezes contraditórias ou não resolvidas. [...] $\mathrm{O}$ próprio processo de identificação, através do qual nos projetamos em nossas identidades culturais, tornou-se mais provisório, variável e problemático. [...] A identidade tornou-se uma "celebração móvel": formada e transformada continuamente em relação às formas pelas quais somos representados ou interpelados nos sistemas culturais que nos rodeiam (p. 12-13).

Pelas respostas percebemos que os professores trazem consigo um imaginário totalizante do conceito de classe social. Da mesma forma, torna-se um problema a homogeneização por faixa etária a partir da qual os alunos são enquadrados num grupo específico devido à idade, como se todos vivessem angústias e desafios da mesma forma. "A prática escolar, nessa lógica, desconsidera a totalidade das dimensões humanas dos sujeitos - alunos, professores e funcionários - que dela participam" (DAYRELL, 2006, p. 139). A homogeneização dos sujeitos não pode ser apontada como um discurso exclusivo dos professores sobre os seus alunos. Precisamos ampliar o foco da análise para perceber que esta situação é coerente com a institucionalização do espaço escolar (MARTINS; CARRANO, 2011). Segundo Dayrell (2006), "a homogeneização dos sujeitos como alunos corresponde à homogeneização da instituição escolar compreendida como universal" (p. 139). O autor chama atenção para a necessidade de que a diversidade cultural não seja limitada à dimensão das classes sociais ou à de idade, sob pena de, se isso acontecer, os alunos não serem reconhecidos como sujeitos socioculturais com sentimentos, expectativas e experiências de vida diversos afetados por relações de classe e etárias, mas não limitados a elas.

[...] esses jovens que chegam à escola são o resultado de um processo educativo amplo, que ocorre no cotidiano das relações sociais, quando os sujeitos fazem-se uns aos outros, com os elementos culturais a que têm acesso, num diálogo constante com os elementos e com as estruturas sociais onde se inserem e a suas contradições (DAYRELL, 2006, p. 142).

Para que aconteça essa virada na percepção dos professores sobre os alunos como sujeitos protagonistas das suas vidas, a escola também precisa ser vista como um espaço sociocultural amplo onde ocorrem as relações sociais entre os sujeitos e a instituição. Especificamente a este respeito - jovens e escola -, já se disse em outro texto e se reafirma agora que

a inquietação das juventudes que buscam a escola [...] resulta mais evidente do que no passado. Ao aprendizado dos conhecimentos escolares são conferidos significados diferentes afetados pelas realidades dos educandos. Vários movimentos sinalizam no sentido de que a escola precisa ser ressignificada para responder aos desafios colocados pelos jovens (MEINERZ; FISS; OGIBA, 2013, p. 15).

Dentre as respostas, percebemos que sete estabelecem um tensionamento em relação à perspectiva homogeneizadora problematizada por Dayrell (2003; 2006). Chamamos de ponto de fuga o efeito de sentido identificado no conjunto de respostas em que os professores evidenciam tanto a compreensão da escola como espaço de sociabilidade e produção das culturas juvenis em suas multiplicidades quanto o entendimento de que esse educando está se constituindo a partir de registros culturais diversos. $\mathrm{O}$ que não significa a inexistência de referência à dimensão do conhecimento na escola como, por exemplo, nos depoimentos dos professores E e D. Tais indícios foram agrupados segundo os sentidos que escoam deles:

1. sentido de escola como espaço de sociabilidade: "Costumo dizer que a escola perdeu seu cunho educacional para virar um ambiente de convívio social" (P1); "Alguns veem na mesma um espaço de socialização e acolhida importantes" (EF); "Entretanto, percebo outros motivos também: socialização entre pares, conhecimentos diferentes, sanar curiosidades, etc.” (P4); “Acredito que vão à escola para tornarem-se cidadãos, que saibam conviver em sociedade [...]" (E);

2. sentido de escola desde a dimensão do conhecimento: "Creio que os alunos sintam-se motivados a ir à escola pelo desejo da descoberta" (J); "Entendo que meus alunos vêm para a escola para aprender [...]" (D); "Entretanto, percebo outros motivos também: socialização entre pares, conhecimentos diferentes, sanar curiosidades, etc." (P4); “[...] e para que [...] desenvolvam conhecimentos básicos" (E).

A escola tem uma multiplicidade de sentidos. Não pode ser compreendida como um dado universal, com sentido único, sendo necessário levar em conta que seu espaço, seus tempos, suas relações podem estar sendo significados de forma diferenciada no discurso pedagógico, tanto pelos estudantes quanto pelos docentes, dependendo da cultura e projeto dos diversos grupos sociais. Sobre o significado da escola, Dayrell (2006) distingue: lugar de encontrar 
e conviver com os amigos; lugar onde se aprende a ser educado; lugar onde se aumentam os conhecimentos; lugar onde se tira diploma e que possibilita passar em concursos. Em investigação mais recente, Machado (2012) entrevistou 90 alunos das totalidades finais de uma escola pública municipal de Porto Alegre. Destacou que estes sujeitos "procuram a escola motivados por adquirir conhecimentos, pertencer a um grupo social que os acolha e, ao mesmo tempo, mudar sua condição de vida" (p. 55). Nas duas pesquisas, constata-se associação da instituição educativa a práticas de socialização pelo convívio que os educandos mantêm com colegas, residindo aí um fator que é considerado como de muita relevância por eles. A partir das respostas dadas pelos professores entrevistados em nossa investigação, constatou-se o mesmo: a escola é considerada a partir de diferentes aspectos que oscilam da dimensão do encontro para a dimensão do conhecimento.

Dayrell (2006) vê como ponto positivo a escola ser um local de socialização: a diversidade cultural "faz com que os indivíduos possam articular suas experiências em tradições e valores, construindo identidades cujas fronteiras simbólicas não são demarcadas apenas pela origem de classe" (p. 143). E problematiza o fato de que são poucos os momentos em que é permitido aos alunos se relacionarem, se significarem neste lugar de afetos a partir do qual a compreendem - o que, quando feito, pode equivaler a uma transgressão. Ele defende a possibilidade de os alunos se expressarem, nos espaços escolares, nas suas diferenças e multiplicidades desde que, como destaca P1 em sua resposta, os alunos "são diversos, não só por serem "rostos diferentes", mas por terem culturas diferentes, famílias diferentes, ideias diferentes".

$\mathrm{O}$ efeito de sentido escola como obrigação, desejo ou necessidade se manifesta em 11 respostas nas quais os professores declaram que os interesses dos alunos em estar na escola partem de duas origens distintas - uma exterior a eles (obrigação e necessidade) e outra associada ao desejo (de conhecimento ou de convívio) dos próprios estudantes, como está apresentado a seguir:

1. escola como obrigação: "pela importância dada a ela por seus pais [...]" (D); "mais por obrigação mesmo" (EF); "por ser uma 'obrigação"” (P3); "porque a sociedade assim o dita e é uma exigência dos pais" (P2); "por influência dos pais" (AC); "Por obrigação, por causa dos pais, porque tem uma lei que manda as crianças para escola e que pune os responsáveis que não obedecerem" (Z); "porque são, muitas vezes, obrigados pelos pais" (J);

2. escola como necessidade: "para que a família receba o Bolsa Família, outros vão para se alimentar [...]" (ME); "porque tem comida" (AC);
3. escola como desejo (de conhecimento ou de convivio): "porque realmente gostam de estar ali" (P3); "por considerar a Escola importante" (ME); "para ocupar seu tempo, não ficar na rua, ter com quem socializar" (P1); "gostam da escola e notam nela algum futuro" (J); "Alguns realmente estão interessados em aprender [...] e alguns vão pelo convívio social" (Z)

Os pais e os programas sociais de redistribuição de renda são mencionados como fatores externos que obrigam a permanência dos alunos. Articula-se também a crença de que a escola se constitui como promessa de mobilidade, que será discutida na próxima categoria. Observamos que algumas dessas respostas podem encaminhar para a construção de estereótipos, pois, ao evidenciarem os pertencimentos sociais dos alunos, os professores podem legitimar um discurso de vitimização dos estudantes oriundos de classes populares. Um exemplo disso é o depoimento de ME que evidencia a existência de uma relação entre a frequência escolar e o cadastro no Programa Social Bolsa Família.

Já nos depoimentos de EI, EF, P3, P2, J, AC e Z, a escola é referida como local para o qual o aluno é encaminhado por vontade dos pais, uma obrigação. Contudo, em outros depoimentos, os mesmos professores P3, P2, J e Z fazem uma relação entre a permanência na escola e os diversos desejos dos alunos. Eles mencionam tanto o desejo de construção de conhecimento quanto o de socialização entre pares.

Um outro efeito de sentido percebido foi chamado de escola como promessa, pois, em nove respostas, os professores dizem que os alunos frequentam a escola pela esperança de um futuro melhor, mencionando a expectativa de ascensão social.

"Eu acredito que todos frequentam a escola pela importância dada a ela por seus pais, que veem um futuro [econômico] melhor para os seus filhos através da educação" (D).

"Acho que esperam um futuro melhor, mas é mais por obrigação mesmo. [...] Muitos encontram na escola um espaço para aprender, ampliar conhecimentos e ascender socialmente" (EF).

"Eles vêm para a escola em busca de melhor condição de concorrer depois ao mercado de trabalho" (FJS).

"Eles vão à escola porque seus pais esperam uma formação que os encaminhe para o acesso à vida profissional" (ASW).

"Alguns vêm porque são, muitas vezes, obrigados pelos pais, outros realmente gostam da escola e notam nela algum futuro" (J).

"Claramente, o principal motivo da ida à escola é o estudo para aprovação e admissão no Colégio Militar" (P4). 
"Na grande maioria dos casos, eles procuram a Escola porque precisam concluir o Ensino Médio e assim garantir um emprego melhor" (MM).

"Para eles [alunos do NEEJA] o diploma é condição de melhores salários, portanto seguem estudando. [...] A escola da rede privada é tanto de ensino fundamental [séries finais] quanto de ensino médio, os quais vão à escola porque os pais obrigam e querem resultados futuros" (FC).

Em certa medida, estes efeitos de sentido (homogeneização do sujeito; ponto de fuga; escola como obrigação, desejo ou necessidade; escola como promessa) dialogam entre si. As motivações para a permanência na escola ultrapassam o processo de ensino e aprendizagem para irem ao encontro do campo da promessa de um futuro mais próspero em relação ao presente. No entanto, como destaca Miletto (2009), este é um caminho perigoso e incerto:

\begin{abstract}
a manutenção da crença no poder mítico da educação como elemento de ascensão social constitui-se, verdadeiramente, como um importante instrumento de controle social interno ou consensual, ou na formulação gramsciana como uma forma de obter o consentimento ativo dos governados. É evidente que a ascensão social de alguns indivíduos, embora não possa ser desprezada do ponto de vista dos dinamismos da sociedade, pouco significa se considerarmos a permanência de uma estrutura econômica que produz continuamente exclusões [...], nutrindo-se da imensa desigualdade, da desumana miséria e exploração da maioria dos trabalhadores (p. 114).
\end{abstract}

Considerando, também, os eventuais riscos e decepções associados à compreensão da escola como promessa, Marilia Sposito (2010) demonstra a necessidade de saber, manifesta pelas classes populares, que vislumbravam, e possivelmente ainda vislumbram, a possibilidade de ascensão social pela escolarização. Ao que parece, quando lutam por escola e educação, certos grupos sociais estão buscando melhor qualificação e, por conseguinte, acesso a maiores oportunidades de inserção no mundo do trabalho com melhores salários.

\section{2 "Como você constrói o seu planejamento? Você o modifica ao longo do ano?"}

Caldeira (2002) e Sacristán $(2000 ; 2007$ c) destacam a importância dos professores construírem seus planejamentos de modo a reconhecer que a prática docente é uma ação pedagógica e política carregada de intencionalidades. Por isso, tornou-se relevante indagar aos professores como eles planejam suas aulas.
Nas respostas dos professores foram reconhecidos três efeitos de sentido que também dialogam entre si: o de planejamento imposto e liberdade; o de planejamento coletivo; e o de autonomia e flexibilidade.

$\mathrm{O}$ efeito de sentido planejamento imposto e liberdade manifesta-se em cinco enunciados de professores que disseram receber o planejamento já determinado pela escola ou, então, obedecer ao que está prescrito na legislação - o que lembra os níveis de currículo apresentado para o professor e prescrito respectivamente. Contudo, os professores também evidenciam que existe a possibilidade de contestação. O currículo, mesmo sendo apresentado, sofre alterações à medida que é apropriado e ressignificado por eles.

"Eu recebo o planejamento da coordenação pedagógica da escola em que eu trabalho; nós temos os conteúdos que temos que trabalhar durante todo o ano" (EI).

"O planejamento é construido a partir das orientações curriculares da escola, mas buscando um espaço de autonomia para distribuir os conteúdos específicos ao longo do calendário e eleger as atividades de ensino que considero mais adequadas dentro dos objetivos traçados" (ASW).

"Trabalhamos com uma coleção de livros, portanto o planejamento é realizado de acordo com a proposta do material. Realizamos em anexo os projetos paralelos, estes vêm para aliar o conteúdo abordado no livro a atividades que pedem mais dinâmicas. Ao longo do ano sempre é necessário realizar algumas adequações de acordo com o desenvolvimento que os alunos apresentam" (J).

"Eu construo o meu planejamento aula a aula. Costumo modificá-lo constantemente durante o ano. Nós recebemos uma grade de conteúdos para serem trabalhados durante o ano e o professor tem liberdade para decidir quanto tempo vai ser dedicado para cada um dos conteúdos" (Z).

"O planejamento depende da Escola onde trabalho. Em escolas particulares temos que levar cada atividade para a coordenação e ver se eles aprovam" (MM).

Aqui se evidencia um tensionamento: por um lado, a situação dos professores que apenas recebem os planejamentos prontos e, por outro, os depoimentos sobre formas de apropriação crítica deles. Esta instabilidade de sentidos associada ao ato de planejar pode ser aproximada tanto do paradigma dominante quanto do paradigma emergente (SANTOS, 1988). Mantém-se a rigidez de conhecimentos listados e prescritos, porém ainda há a possibilidade de uma transgressão por parte dos sujeitos. 
$\mathrm{O}$ efeito de sentido planejamento coletivo foi pensado a partir respostas dos professores que trabalham com a dinâmica da docência compartilhada (pensam o planejamento e desenvolvem a prática pedagógica junto com outros colegas) e daqueles que trabalham em escolas que optam por planejamento por projetos.

"Na minha Escola trabalhamos com a Docência Compartilhada e muitos planejamentos são feitos em grupo. Modifico ao longo do ano, muitas vezes" (ME).

"O planejamento é construido coletivamente, por trimestre. Normalmente a escola trabalha com algum projeto em comum" (EF).

"Planejo as minhas aulas conforme as necessidades e os interesses dos meus alunos; sendo assim, meu planejamento é flexível" (P3).

"Trabalhamos com uma coleção de livros, portanto o planejamento é realizado de acordo com a proposta do material. Realizamos em anexo os projetos paralelos, estes vêm para aliar o conteúdo abordado no livro a atividades que pedem mais dinâmicas. Ao longo do ano sempre é necessário realizar algumas adequações de acordo com o desenvolvimento que os alunos apresentam" $(\mathrm{J})$.

"Tem projetos transdisciplinares envolvidos nestes temas, como, por exemplo, a questão africana ou a questão da identidade indígena" (Z).

"Planejo e executo minhas aulas através de projetos e atividades significativas, e sempre que existe a necessidade o planejamento é modificado. $\mathrm{O}$ professor precisa ter essa autonomia para seguir seu trabalho" (D).

Ele se aproxima do paradigma emergente de Santos (1988), mas merece cuidado na sua explicação. A disciplina escolar é colocada como um saber à disposição dos alunos: pode ser passível de transgressão, mutação e até mesmo (re)criação. Ao falar a respeito de uma ciência pós-moderna, Santos (1988) evidencia a importância de que os temas a serem pesquisados sejam "galerias por onde os conhecimentos progridem ao encontro uns dos outros. [...] o conhecimento avança à medida que o seu objetivo se amplia, ampliação que, como da árvore, procede pela diferenciação e pelo alastramento das raízes em busca de novas e mais variadas interfaces" (p. 65). Ao invés de áreas de conhecimento setorizadas, "a fragmentação pós-moderna é [...] temática" (idem). O planejamento pedagógico possibilita incorporar a agência dos alunos como sujeitos que podem contribuir com outros saberes acerca dos conhecimentos a serem produzidos no cotidiano escolar.

Das respostas, em 12 delas surge a necessidade que os professores têm de adaptar seus planejamentos.
$\mathrm{O}$ efeito de sentido autonomia e flexibilidade expressa esse exercício de revisão contínua das aulas, bem como a possibilidade dos professores imprimirem características de suas individualidades:

"Cada professor tem autonomia e flexibilidade de alterar esse planejamento conforme o interesse ou necessidade do grupo que atende. Planejo os conteúdos que darei no início do ano organizando através dos trimestres. Às vezes é preciso mexer pelo mau ou bom andamento das turmas" (EF).

"Planejo e executo minhas aulas através de projetos e atividades significativas, e sempre que existe a necessidade o planejamento é modificado" (D).

"Meu planejamento é feito baseado no programa da disciplina e nas características individuais de cada turma. Ele vai se modificando se for vista a necessidade" (FJS).

"Construo meu planejamento semanalmente e muitas vezes preciso modificá-lo" (P4).

“Às vezes modifico o planejamento. Isso é bastante perceptível ao comparar duas ou mais turmas da mesma série, que apresentam diferente apreensão/construção dos conhecimentos trabalhados" (ASW).

"Planejo as minhas aulas conforme as necessidades e os interesses dos meus alunos; sendo assim, meu planejamento é flexível" (P3).

"Procuro encontrar formas de construir meu planejamento que ajudem no aprendizado do aluno" (P1).

"Meu planejamento é construído através da realidade do meu aluno. Meu planejamento nunca é fixo, fechado, está sempre em modificação de acordo com os interesses que vêm surgindo" (E).

"Eu construo o meu planejamento aula a aula. Costumo modificá-lo constantemente durante o ano" (Z).

"Modifico durante o ano, sim! Infelizmente, lidamos com tempos restritos, feriados, faltas de alunos, dificuldades de cada turma. Então isso influencia no desenvolvimento do meu planejamento" (MM).

"Primeiramente através dos interesses dos alunos adequando-os dentro do possível à disciplina" (FC).

"O planejamento é construido levando-se em consideração o conteúdo a ser desenvolvido e também as peculiaridades da turma e como ele é flexível, é passível de modificações sempre que for necessário" (P2).

Ao falar sobre as variáveis que provocam alterações no planejamento pensado e, portanto, exigem 
flexibilidade por parte do docente, elementos de quatro ordens diferentes são considerados pelos professores entrevistados:

1. relacionados ao grupo de alunos: interesses, necessidades, características, desempenho, realidades, curiosidades, dificuldades, ausências (faltas);

2. relacionados à instituição ou a outro tipo de norma: programa da disciplina, tempo restrito;

3. situações inusitadas: "acontecimentos que fogem a qualquer teoria pensada com antecedência" (P4);

4. escolhas metodológicas do professor: modo de produzir a ação docente, preocupação com a criação de situações de aprendizagem.

Sob certo aspecto, a revisão dos planejamentos acontece devido ao choque dos interesses dos professores com as novidades e diferenças que os alunos imprimem ao cotidiano escolar. O planejamento prévio dos professores passa a não funcionar, de modo que se reconhecem sua desconexão com a realidade apresentada e produzida na sala de aula. A este respeito, Dayrell (2006) lembra que "os alunos já chegam à escola com um acúmulo de experiências vivenciadas em múltiplos espaços, através dos quais podem elaborar uma cultura própria, uns "óculos" pelo qual veem, sentem e atribuem sentido e significado ao mundo, à realidade onde sem inserem" (p. 141).

Geraldi (2010) defende que cada aula é um acontecimento e, por isso, se torna importante que os professores exercitem sua sensibilidade em reconhecer os seus alunos como sujeitos dinâmicos e ativos dentro da instituição escolar. A modificação dos planejamentos em função do inusitado e de variáveis relacionadas especificamente ao grupo de alunos evidencia a possibilidade de estes interferirem na prática docente como autores dela também. Ademais, reforça o que Gómez (2007) aponta como tarefas da escola que lhe são próprias em sua função educativa: utilizar o conhecimento, também social e historicamente construído e condicionado, como ferramenta de análise para compreender, para além das aparências superficiais do status quo real - assumido como natural pela ideologia dominante -, o verdadeiro sentido das influências de socialização e os mecanismos explícitos ou disfarçados que se utilizam para sua interiorização pelas novas gerações; e provocar/facilitar a reconstrução dos conhecimentos, atitudes e formas de conduta que os alunos assimilam direta e acriticamente nas práticas sociais de sua vida anterior e paralela à escola. Em resumo, e citando literalmente o autor, o princípio básico a orientar a ação na escola precisa assumir compromissos com a produção de situações que favoreçam a "participação ativa e crítica dos/as alunos/ as nas diferentes tarefas que se desenvolvem na aula" (GÓMEZ, 2007, p. 26).
A vida da escola, como a de qualquer outro grupo ou instituição social, pode ser descrita como um cenário vivo de interações onde se intercambiam ideias, valores e interesses diferentes e seguidamente conflitantes. Nela, "os alunos [...] se apropriam dos espaços, que a rigor não lhes pertencem, recriando neles novos sentidos e suas próprias formas de sociabilidade" (DAYRELL, 2006, p. 147). Os docentes, em alguns casos, acreditam "governar a vida da aula quando apenas dominam a superfície" (GÓMEZ, 2007, p. 19), ignorando a riqueza dos intercâmbios latentes. No entanto, a flexibilidade no planejamento, evidenciada em muitos dos enunciados dos professores entrevistados, aponta para a abertura, por parte do docente, de um espaço de relativa autonomia que desequilibra a escola em seu tradicional papel reprodutor. Quando os professores afirmam que repensam o planejamento em função de interesses e peculiaridades das turmas, quando E esclarece que seu planejamento é elaborado a partir da realidade de seu aluno, evidencia-se certa preocupação com uma ação na qual as "diferenças [...] devem ser enfrentadas como um desafio pedagógico dentro das responsabilidades habituais do profissional docente" (GÓMEZ, 2007, p. 24) ao que se soma a necessidade de que cada aluno seja considerado desde a sua situação real.

Sacristán $(2000 ; 2007 c)$, esclarece que a compreensão globalizadora de planejamento implica que o professor se coloque a tarefa de criar situações a partir das quais os alunos vivam experiências de aprendizagem significativas ao longo de sua história e tempo de escolarização. A esse respeito, cabe citar o depoimento de P1 quando relata que "Procuro encontrar formas de construir meu planejamento que ajudem no aprendizado do aluno", aproximando-se desta compreensão. De modo tenso, dialogam com tais elementos alguns outros apontados por MM: "tempos restritos, feriados, faltas de alunos" que influenciam no planejamento de um modo diferente do que se considerou antes. Essas variáveis dizem respeito a condições materiais do trabalho sobre as quais o professor não tem ingerência: ele não costuma ter em suas mãos a possibilidade de mudar tais condições e, nessa mesma medida, não é ele autonomamente quem pode decidir de forma total o que é e será sua prática profissional.

Dito de outra forma, podemos perspectivar que o professor escolhe tarefas, pensa modos de realizá-las, mas trabalha dentro de um quadro no qual algumas são possíveis e outras não - o que remete, também, aos vários níveis de objetivação do currículo e aos seus efeitos sobre as ações pedagógicas. Algo de que nos lembra P4 quando revela que "Construo meu planejamento semanalmente e muitas vezes preciso modificá-lo em função de acontecimentos que fogem a qualquer teoria pensada com antecedência". Ou seja, "O professor também enfrenta 
uma situação complexa e incerta na qual 'é um problema encontrar $o$ problema'. Ao tratar de casos únicos não pode aplicar teorias ou técnicas-padrão, mas um processo de reflexão e de escolhas nas condições concretas da situação prática" (SACRISTÁN, 2000, p. 169). Da mesma forma que o plano de trabalho (ou de ensino, como também é chamado neste texto), o planejamento dos professores não se traduz como execução de práticas ajustadas a normas técnicas, mas na realização destas ações dos mais diversos modos, referentes a alguns alunos, em certas situações, diante de determinadas condições, em tempos variados etc. Muitos são os componentes constitutivos da ação de planejar, de produzir currículo, de produzir docência, e eles correspondem, conforme Sacristán (2007c), a aspectos para os quais o docente precisa prestar atenção em seu processo de reflexão e deliberação sobre a prática.

Desde uma compreensão de docência-autora ${ }^{4}$, negase a figura do professor como mero desenvolvedor do currículo, executor de diretrizes anteriores a ele de modo acrítico e desprofissionalizado. "O currículo pode exigir o domínio de determinadas habilidades relacionadas com a escrita, por exemplo, mas só o professor pode escolher os textos mais adequados para despertar o interesse pela leitura com um grupo de alunos" (SACRISTÁN, 2000, p. 168). Dito de outra forma, propor o currículo como espaço teórico-prático, como processo de deliberação no qual os professores participam como profissionais capazes, comprometidos com as necessidades educativas de seus alunos, envolve reconhecer os obstáculos e desafios objetivos e subjetivos que atravessam a atuação profissional, e o professor, em suas artes de produzir currículo na Educação Básica, bem como os dilemas fundamentais diante dos quais o professor, em sua ação de planejar, precisa fazer escolhas.

\section{A título de CONCluSÃo}

Retomando os argumentos e referenciais com que trabalhamos, percebemos vários movimentos distintos e tensos na fala dos professores, evidenciando-se um deslocamento constante de referenciais mais identificados com o paradigma dominante em alguns momentos e, em outros, mais próximos do paradigma emergente. Surpreendemos, ao longo dos gestos de análise dos enunciados extraídos dos depoimentos dos professores entrevistados, o mesmo professor em processo de deslocamento de um ponto de vista para outro: EF, D, P2 e P3 se reportam aos estudantes considerando somente sua classe social e/ou grupo etário, silenciando sobre outras marcas culturais também constitutivas desses sujeitos e de seus modos de estabelecer relações. Os alunos são tomados de uma forma homogeneizadora que permite especular sobre uma escola ainda compreendida como estrutura fechada, totalizante e universal, portanto, pensada a partir do paradigma dominante. Desde esta perspectiva, os sujeitos vão sendo alocados e ajeitados para uma dinâmica institucionalizadora que coloniza também os currículos e as aulas.

Ao mesmo tempo, EF declara que seu "planejamento é construído coletivamente", e P2 acrescenta que considera as peculiaridades da turma. Além de EF e P2, outros dois professores se juntam ao grupo dos que flexibilizam os planos em função dos interesses e das necessidades manifestos pelos alunos. Em outras palavras, ainda que interpretem seus alunos sem considerá-los a partir da complexidade de relações que experimentam e pelas quais são formados, eles não silenciam os alunos no momento de planejar o trabalho e desenvolvê-lo. Movimentos como esses remetem ao próprio modo de constituição das identidades docentes: móvel, híbrido, afetado por fatores os mais variados e, às vezes, antagônicos. E, de modo semelhante, autorizam falar sobre o currículo como "terreno em que se enfrentam diferentes e conflitantes concepções de vida social, [...] aquilo pelo qual se luta e não aquilo que recebemos" (MOREIRA; SILVA, 2005, p. 27). Aquilo que se inventa, que se cria, que não está totalmente dado se entendermos que a prática de ensino e o desenvolvimento do currículo são processos indeterminados.

Em razão de todos os argumentos apresentados e sem esquecer os deslocamentos de posição efetuados pelos docentes entrevistados - deslocamentos a partir dos quais se evidenciam identidades que não se fixam num ponto de vista único -, permanece sendo um desafio contemporâneo para os professores enxergar seus alunos como sujeitos com uma trajetória de vida específica. A escola precisa permitir-se ser um local polissêmico, onde se faça presente a multiplicidade de sentidos dos saberes através das experiências vividas no cotidiano das pessoas. Produzir um planejamento que tenha intencionalidade e, ao mesmo tempo, seja flexível se mostra como um segundo desafio ao trabalho docente. Vários professores, em suas respostas, afirmam esta flexibilidade como característica de seu planejamento - EF, D, FJS, ASW, P1, P2, P3, P4, E, Z, MM. No entanto, isso não elimina o compromisso de continuar insistindo na importância de o ensino ser visto como arte - o que não significa improviso nem ausência de regras. Pensar o ensino como arte, o docente como autor, se apoia em realidades às quais os professores com quem conversamos fizeram referência.

Motivar um exercício de alteridade, onde os professores se coloquem no lugar de alguém que descobre o mundo a partir da investigação curiosa com auxílio de outros sujeitos (os seus alunos, por exemplo), pode ser um caminho fértil para mudanças pessoais e coletivas de que resultem a invenção de outras propostas possíveis 
de metodologias, planos de ensino e práticas docentes. Propostas de planejar, propostas de ensinar que contem com as práticas já encenadas na escola e ousem ir além delas. O horizonte mais longe é a transformação da instituição escolar a partir da possibilidade dos alunos a habitarem de uma forma que os acolha como sujeitos socioculturais, e assim ocorra também com os professores. Não ousamos propor estratégias para esta escola, mas sim desafios de autorreflexão e autorreinvenção por parte dos docentes a partir das realidades que os alunos produzem e manifestam.

\section{REFERÊNCIAS}

CALDEIRA, Anna Maria Salgueiro. Elaboração de um projeto de ensino. Presença Pedagógica, Belo Horizonte, Dimensão, v. 8, n. 44, p. 13-23, mar.-abr. 2002.

CHOPPIN, Alain. História dos livros e das edições didáticas: sobre o estado da arte. [on-line] Revista Educação e Pesquisa, São Paulo, v. 30, n. 3, p. 549-566, set.-dez. 2004. Tradução de Maria Adriana C. Cappello. Disponível em: <http://www.scielo. br/pdf/ep/v30n3/a12v30n3.pdf >. Acesso em: 20 fev. 2008.

DAYRELL, Juarez. T. O jovem como sujeito social. Revista Brasileira de Educação, São Paulo, n. 24, p. 40-52, set.-dez. 2003.

DAYRELL, Juarez. T. escola como espaço sócio-cultural. In: DAYRELL, Juarez. T. (Org.). Múltiplos olhares sobre a educação e cultura. Belo Horizonte: Editora UFMG, 2006. p. 136-161.

EMMEL, Rubia; ARAÚJO, Maria Cristina Pansera de. A pesquisa sobre o livro didático no Brasil: contexto, caracterização e referenciais de análise no período 1999-2010. SEMINÁRIO DE PESQUISA EM EDUCAÇÃO NA REGIÃO SUL - ANPED Sul, 9., 2012. Anais... Universidade de Caxias de Sul: Caxias do Sul, julho de 2012. Texto digitalizado.

FISS, Dóris Maria Luzzardi. Os processos de construção da autoria e do mal-estar docente numa escola pública estadual. 1998. Dissertação (Mestrado em Educação) - Faculdade de Educação, Universidade Federal do Rio Grande do Sul, Porto Alegre, 1998.

FISS, Dóris Maria Luzzardi. A aprendizagem dos abraços ou o dizer a palavra: espaços de autoria e de diálogo. Diálogo, Canoas, Centro Universitário La Salle, p. 77-104, 2000.

FISS, Dóris Maria Luzzardi. Territórios incertos: os processos de subjetivação das professoras da rede pública estadual. 2003. Tese (Doutorado em Educação) - Faculdade de Educação, Universidade Federal do Rio Grande do Sul, Porto Alegre, 2003.

FISS, Dóris Maria Luzzardi. Autoria nos processos de formação continuada da educação de jovens e adultos. In: FISS, Dóris Maria Luzzardi et al. (Org.). Identidades docentes: educação de jovens e adultos, linguagem e transversalidades. Rio de Janeiro: Lamparina, 2010. p. 37-58.

FREITAG, Barbara; MOTTA, Valéria Rodrigues; COSTA, Wanderly Ferreira. $O$ estado da arte do livro didático no Brasil. Brasília: Inep, 1987.

GERALDI, João Wanderley. A aula como acontecimento. São Carlos: Pedro \& João Editores, 2010.
GÓMEZ, A. I. Pérez. As funções sociais da escola: da reprodução à reconstrução crítica do conhecimento e da experiência. In: SACRISTÁN, Gimeno; GÓMEZ, A. I. Pérez (Org.). Compreender e transformar o ensino. 4. ed. Porto Alegre: Artmed, 2007. p. 13-26.

HALL, Stuart. A identidade cultural na pós-modernidade. 7. ed. Rio de Janeiro: DP\&A, 2003.

MACHADO, Jeferson Ventura. Educação de jovens e adultos: encantamento e permanência. 2012. Monografia (Especialização em Educação) - Faculdade de Educação, Universidade Federal do Rio Grande do Sul, Porto Alegre, 2012.

MARTINS, Carlos H. S.; CARRANO, Paulo C. R. A escola diante das culturas juvenis: reconhecer para dialogar. Revista Educação, Santa Maria, UFSM, v. 36, n. 1, jan.-abr. 2011.

MEGID NETO, Jorge; FRACALANZA, Hilário. O livro didático de ciências: problemas e soluções. In: FRACALANZA, Hilário; MEGID NETO, Jorge (Org.). O livro didático de ciências no Brasil. Campinas: Komedi, 2006.

MEINERZ, Carla Beatriz; FISS, Dóris Maria Luzzardi; OGIBA, Sônia Mara Moreira. Formação de professores e práticas culturais: descobertas, enlaces, experimentações. Arquivos Analíticos de Políticas Educativas, v. 21, n. 22, 2013. Dossiê Formação de professores e práticas culturais: descobertas, enlaces, experimentações. Disponível em: $<$ http:// epaa.asu.edu/ojs/article/view/1140>. Acesso em: 12 set. 2013.

MILETTO, Luiz Fernando Monteiro. "No mesmo barco, dando força, um ajuda o outro a não desistir" - Estratégias e trajetórias de permanência na educação de jovens e adultos. 2009. Tese (Doutorado em Educação). Faculdade de Educação, Universidade Federal Fluminense, Niterói, 2009.

MINAYO, Maria Cecília de Souza (Org.). Pesquisa social: teoria, método e criatividade. 25. ed. Petrópolis: Vozes, 2007.

MOREIRA, Antonio Flávio; SILVA, Tomaz Tadeu da (Org.). Currículo, cultura e sociedade. 8. ed. São Paulo: Cortez, 2005.

PÊCHEUX, Michel. O discurso: estrutura ou acontecimento. 2. ed. Campinas: Pontes, 1997.

SACRISTÁN, J. Gimeno. O currículo: uma reflexão sobre a prática. 3. ed. Porto Alegre: Artmed, 2000.

SACRISTÁN, J. Gimeno. Âmbitos do plano. In: SACRISTÁN, J. Gimeno; GÓMEZ, A. I. Pérez (Org.). Compreender e transformar o ensino. 4. ed. Porto Alegre: Artmed, 2007a. p. 197-231.

SACRISTÁN, J. Gimeno. O que são os conteúdos do ensino? In: SACRISTÁN, J. Gimeno; GÓMEZ, A. I. Pérez (Org.). Compreender e transformar o ensino. 4. ed. Porto Alegre: Artmed, 2007b. p. 149-195.

SACRISTÁN, J. Gimeno. Plano do currículo, plano do ensino: o papel dos professores/as. In: SACRISTÁN, J. Gimeno; GÓMEZ, A. I. Pérez (Org.). Compreender e transformar o ensino. 4. ed. Porto Alegre: Artmed, 2007c. p. 233-293.

SANTOS, Boaventura de Sousa. Um discurso sobre as ciências na transição para uma ciência pós-moderna. Estudos Avançados, São Paulo, v. 2, n. 2, ago. 1988. Disponível em: $<$ http://www.scielo.br/pdf/ea/v2n2/v2n2a07.pdf $>$. Acesso em: 07 maio 2013.

SANTOS, Boaventura de Sousa. Pela mão de Alice: o social e o político na pós-modernidade. São Paulo: Cortez, 2000. 
SANTOS, Boaventura de Sousa. Conhecimento prudente para uma vida decente. (2. ed.) São Paulo: Cortez, 2006.

SANTOS, Boaventura de Sousa. Um discurso sobre as ciências. 5. ed. São Paulo: Cortez, 2008.

SPOSITO, Marília. A ilusão fecunda: a luta por educação nos movimentos populares. 2. ed. São Paulo: Hucitec, 2010.

\section{NotAs}

1 Agradecemos à Regina Maria Varini Mutti pela importante interlocução a partir da qual aspectos do texto foram reconsiderados de modo a enriquecer a problematização e as análises produzidas.

${ }^{2}$ Uma versão preliminar desta pesquisa, com alguns resultados parciais e seguindo a dinâmica da análise de conteúdo conforme proposta por Laurence Bardin (portanto, diferente da perspectiva metodológica assumida neste texto), foi apresentada no V Seminário Brasileiro de Estudos Culturais e II Seminário Internacional de Estudos Culturais, na ULBRA, em maio de 2012
3 Ao longo das análises, foram grifados os elementos considerados no trabalho de evidenciação dos efeitos de sentidos manifestos nos enunciados que constituem os depoimentos dos professores entrevistados.

${ }^{4}$ Os processos de construção da autoria pelo professor estão diretamente relacionados às várias posições sociais que assume, às negociações culturais que promove, às rupturas produzidas em e por suas práticas políticas e pedagógicas. Portanto, ainda que a escola historicamente se traduza como universo semântico logicamente estabilizado que se sustenta em concepções, por vezes, massificadoras de conhecimento, de professor e de aluno, a consideração dos processos de autoria no espaço e tempo pedagógicos, a compreensão da docência como autora, do docente como autor, produz reviramentos desses sentidos fixos e estabelecidos sobre os espaços escolares (FISS, 2010). A este respeito, convém conferir outros trabalhos que aprofundam o tema: Os processos de construção da autoria e do mal-estar docente numa escola pública estadual (FISS, 1998), A aprendizagem dos abraços ou o dizer a palavra (FISS, 2000) e Territórios incertos (FISS, 2003).

Artigo recebido em julho 2014

Aprovado em novembro 2014. 